\title{
Novel Corrosion Resistant Hard-Coatings for Metal Surfaces
}

\author{
G.W. Wagner, S. Sepeur, R. Kasemann and H. Schmidt \\ Institut für Neue Materialien gem. GmbH, \\ Im Stadtwald, Gebäude 43, D-66123 Saarbrücken, Germany
}

Keywords: Corrosion Protection, Ormocers, Coatings, Mechanical Protection

\begin{abstract}
Using the sol-gel process, novel inorganic-organic composites (ormocers) were synthesized. By controlled hydrolysis and condensation of an epoxy modified alkoxide, a propyl modified alkoxide and an aluminum alkoxide in the presence of fluoride ions, stable sols can be produced. These can be applied by conventional coating techniques (e. g. spray-, spin-, dip-coating) on metal surfaces ( $\mathrm{Al}, \mathrm{Zn}, \mathrm{Mg}$ ) and cured thermally. The high corrosion inhibitant properties are explained by a special metal/coating interface. The transparent coatings show good adhesion, corrosion protection and a high wear resistance avoiding chemical pretreatement (e. g. chromating). These new coatings open a wide field of applications.
\end{abstract}

\section{Introduction}

The mechanical and corrosive protection of metal surfaces are questions of current interest. Usual coating materials based on organic polymers show low scratch- and abrasion resistance as well as a lack of resistance to corrosive impact. In several applications pretreatment steps which cause environmental problems (e. g. pickling, etching, chromating) are necessary. Incorporation of inorganic fillers leads to increased scratch and abrasion resistance of the polymer coatings but the resulting coatings are no more transparent. Sol-gel processing of inorganic-organic nanocomposites with molecular or nano-scaled phase dimensions $(\leq 5 \mathrm{~nm})$ opens the possibility to achieve transparent coatings with improved properties. The basic principles of the sol-gel processing of inorganic-organic composites by incorporation of organic groupings (network modifiers: alkyl, aryl...; network formers: methacryl, epoxy....) linked to the inorganic backbone formed by hydrolysis and condensation (e. g. starting from alkoxides) are described elsewhere [1-7]. Objective of the present study is to synthesize a transparent sol-gel inorganic-organic composite coating with high scratch and abrasion resistance due to in-situ generation of nano-particles and the achievement of good adhesion and corrosion inhibition by a tailored metal/coating interface.

\section{Experimental}

The synthesis of the coating material is shown in figure 1 : 


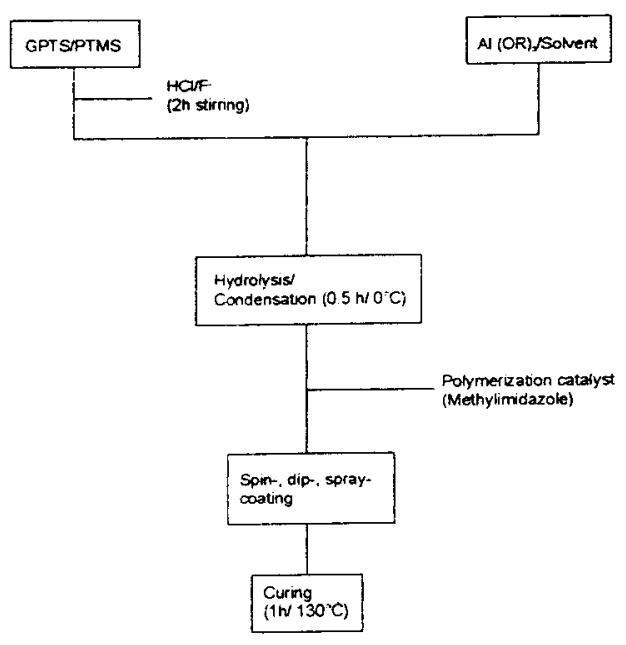

Fig. 1: Synthesis scheme of the coating material [8]

Hydrolysis and condensation were followed by ${ }^{29} \mathrm{Si}-\mathrm{NMR}$ spectroscopy [8] and by photon-correlation spectroscopy (PCS) $[8,9]$ for determination of the synthesized particles in the sol-phase. Coating experiments were carried out by common coating techniques like spin-, dip- or spray coating on the metal surfaces previously degreased with an alkaline surfactant. Curing was carried out at $130^{\circ} \mathrm{C} / 1 \mathrm{~h}$.

\section{Results and discussion}

$\gamma$-glycidyloxipropyltrimethoxysilane (GPTS), propyltrimethoxysilane (PTMS) and an aluminum alkoxide (ASB) were chosen as starting materials for the synthesis. The epoxy group of GPTS generates a poly ethylene oxide network beside the inorganic backbone by organic polymerisation. The propyl containing PTMS is used as an network modifier to increase the relaxation behavior of the material to achieve a more hydrophobic behavior of the material. For determination of the particle growth PCS measurements were performed. No particle generation could be detected during the measurements using $\mathrm{HCl}$ catalysis for hydrolysis and condensation of the alkoxides. When a $\mathrm{HCl} / \mathrm{F}^{-}$catalysis was used particle growth was detected within $6 \mathrm{~h}$ reaction time up to particle sizes of $5 \mathrm{~nm}$ (Fig. 2). 


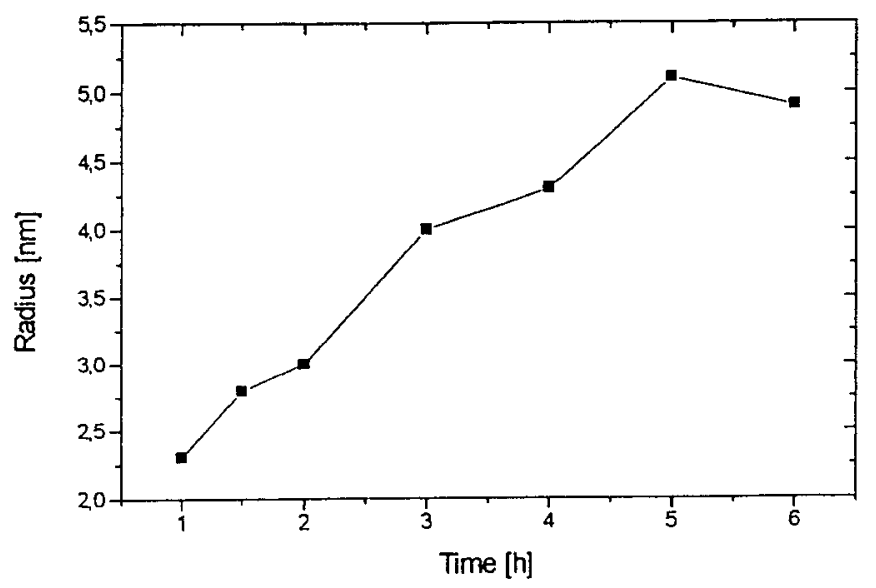

Fig. 2: Particle growth detected by PCS measurements in the system GPTS, PTMS, ASB catalyzed by $\mathrm{HCl}^{-}$

The particle growth caused by the fluoride ions $[10,11]$ is due to the known behavior of fluoride ions as condensation catalyst.

The coating material was applied by conventional coating techniques (e. g. dip-, spray-coating) on the metal surfaces ( $\mathrm{Al}$, zinced steel, $\mathrm{Mg}$ ) and cured thermally at $130^{\circ} \mathrm{C}$. The thickness can be adjusted by variation of the viscosity and the coating conditions between 5 and $25 \mu \mathrm{m}$. The transparent coatings show very good adhesion proven by cross cut/pull-off test (DIN 53 151). The adhesion is unaffected after 4 weeks of wet climate test (DIN 50017). The very good wet climate stability is due to the hydrophobic behavior of the propyl chains within the network. Because of the very good adhesion environmentally damaging surface pretreatments like chromating can be avoided. The excellent adhesion can be explained by chemical links formed by condensation of surface hydroxyl groups of the metal with alkoxides as shown in fig. 3 . 


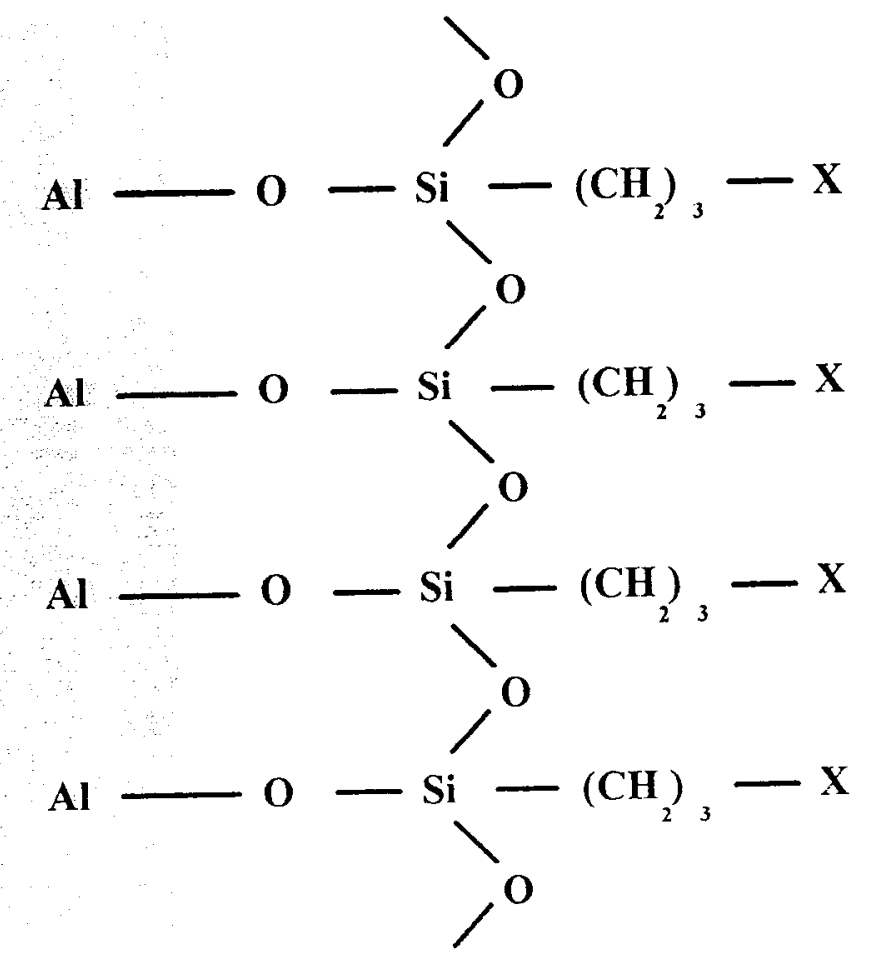

Fig. 3: Scheme of the interface layer metal/coating

The scratch resistance of the coatings was measured by a modified Erichsen test (load on a diamond that is moved on the surface when the first visible scratch on the microscope is detected). The scratch resistance is in the range of 8 to $10 \mathrm{~g}$ for the inorganic-organic composite coating in comparison to $\leq 1 \mathrm{~g}$ for conventional 2component-epoxy polymer coatings. The abrasion resistance was determined by surface roughness measurements before and after the taber abrader test ( 100 cycles taber abrader, DIN 52347 ) and compared to the 2-component-epoxy coating (fig. 4).

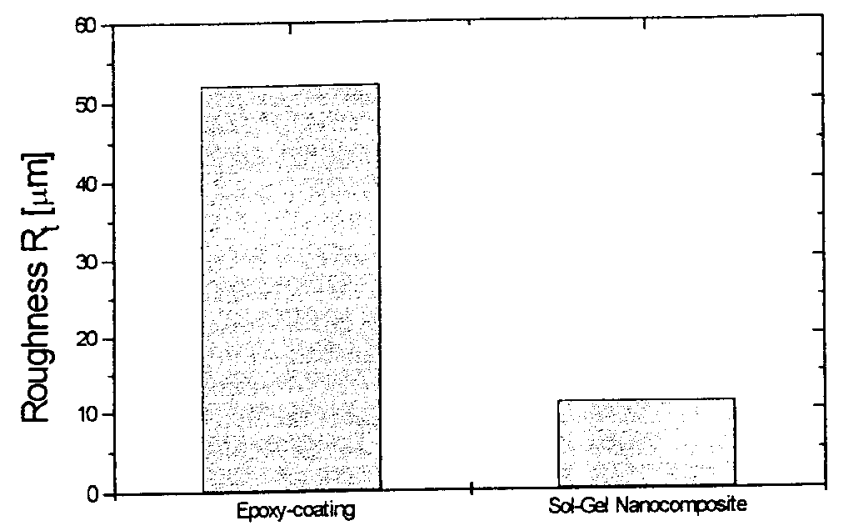

Fig. 4: Surface roughness after taber abrader test for the nanocomposite and the 2component-epoxy coating $\left(R_{t}\right.$ of both coatings before test: 1,2 $\left.\mu \mathrm{m}\right)$ 
The low surface roughness of the nanocomposite coating compared to the epoxy polymer coating (fig. 4) shows the high abrasion resistance of the coating. The high scratch and abrasion resistance of the nanocomposite coating is due to the inorganic backbone and the nanoparticles in the coating.

The corrosion protection properties of the coatings are determined by salt-spray test (DIN 50 021/53 167). Epoxy coated and nanocomposite coated samples with applied cross-cuts before the test, were exposed to salt-spray test for 2 weeks. The epoxy coating shows a high corrosive attack whereas the nanocomposite shows no corrosion. The cross-cuts show no corrosion along the interface of coated and destroyed regions and thereby corrosion inhabitant properties (fig. 5). The reason for this is the very stable tailored metal/nanocomposite interface which act as a chemical link between the metal and the coating.

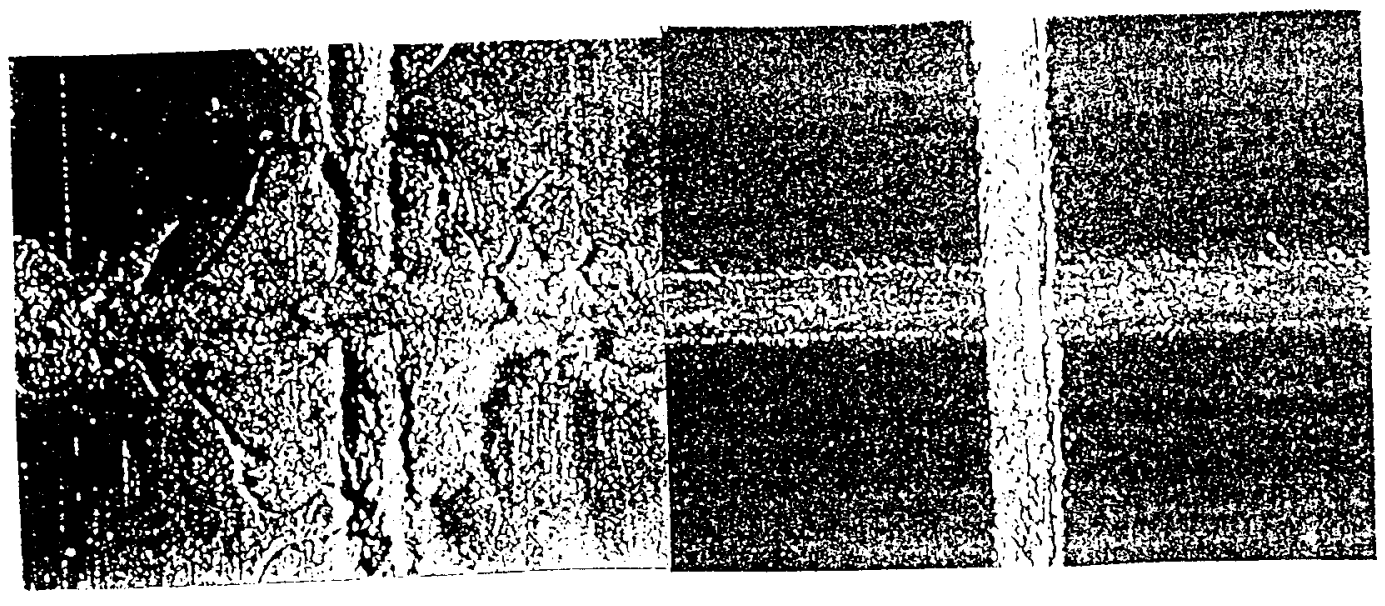

Fig. 5: Comparison between cross-cuts in epoxy coating system (left) and nanocomposite coating on aluminum after 2 weeks salt-spray test

\section{Conclusion}

Coating materials for metal surfaces based on inorganic-organic composites could be synthesized by controlled hydrolysis and condensation. The transparent coatings show very good corrosion protective properties because of tailored interface between metal and coating by oxygem bridges. The good scratch and abrasion properties are attributed to the inorganic backbone in combination with in-situ generated particles. These properties open a wide field of applications for example in the car and aircraft industries. 


\section{Acknowledgement}

The authors want to thank the state of Saarland for financial support.

\section{References}

[1] H. Schmidt, B. Seiferling, G. Philip and K. Deichmann; in: Ultrastructure of Processing of advanced Ceramics, J.D. Mackenzie and D.R. Ulrich (eds.), John Wiley \& Sons, New York (1988), p. 651.

[2] H. Schmidt; Mat. Res. Soc. Symp. Proc. 171 (1990)3.

[3] H. Schmidt; in Chemical Processing of Advanced Materials, L. L. Hench and J. K. West (eds), John Wiley \& Sons, New York (1992).

[4] H. Schmidt, H. Scholze and G. Tünker; J. Non-Cryst. Solids 80 (1989) 557.

[5] H. Schmidt; in Chemical Spectroscopy and Applications of Sol-Gel Glasses; R. Reisfeld, C. K. Joergensen (eds.), Springer, Berlin, Heidelberg (1992).

[6] C. Sanchez; J. Non-Cryst. Solids $147 / 148$ (1992)1.

[7] E. J. A. Pope and J. D. Mackenzie; J. Non-Cryst. Solids 87 (1986) 185.

[8] G. W. Wagner; Master's Thesis, Saarbrücken (1992).

[9] S. E. Bott; ACS Symposium Series 332 (1985).

[10] J. C. Brinker, G. W. Scherer (eds.); Sol-Gel Science, Academic Press, London (1990).

[11] P. W. J. G. Wijnen, R. A. Van Santen et al., J. Coll. Interface Sci. 145 (1991) 370. 
Sol-Gel Production

doi:10.4028/www.scientific.net/KEM.150

Novel Corrosion Resistant Hard-Coatings for Metal Surfaces

doi:10.4028/www.scientific.net/KEM.150.193 